\title{
ExpertInnen im ÖWAV
}

\author{
InterviewpartnerIn: Kajetan Beutle
}

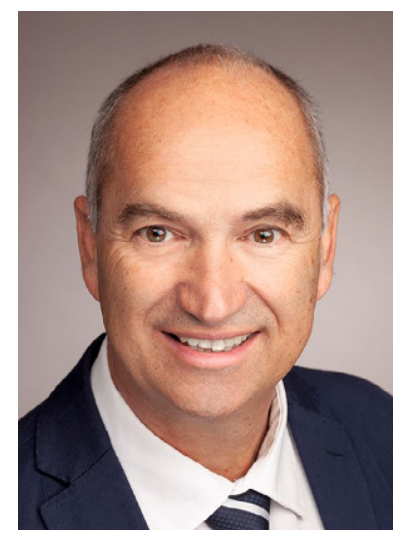

DI DR. Kajetan BEUTLE, Mitglied des ÖWAV-Vorstands, Mitglied des Leitungsausschusses „Abwassertechnik und Gewässer"schutz" und der „Arge Abwasser“

\section{Beschreiben Sie bitte kurz Ihren fachlichen Hintergrund/beruflichen Werdegang.}

Nach Abschluss der HTL-Ortweinplatz, Abteilung Tiefbau, entschied ich mich für das Bauingenieurstudium an der TU Graz, Vertiefung Grundbau, Wasserwirtschaft und -bau. Dem Studienabschluss folgte ein Doktoratsstudium, wo ich im Jahr 1998 promovierte. Weitere Ausbildungsschritte waren die Konzessionsprüfung für den Erwerb eines Technischen Büros für Kulturtechnik und Wasserbau sowie die Ausbildung zur Sicherheitsfachkraft. Im Rahmen des Doktoratsstudiums war ich als Universitätsassistent am Institut für Siedlungswasserwirtschaft und Landschaftswasserbau an der TU Graz beschäftigt. Dabei bot sich die Gelegenheit, dass ich mein erworbenes Wissen bei einem Auslandsaufenthalt in der Stadt Shkodra/Albanien im Rahmen eines Wasserversorgungs-Sanierungsprojektes unter Beweis stellen konnte. 1998 setzte ich meine berufliche Laufbahn als Vertragsbediensteter bei der Stadt Graz im Kanalbauamt fort. Vorerst tätig in der Bauabteilung, wurde ich bald zum Leiter der Planung befördert und 2006 übernahm ich die Leitung der Grundstücksentwässerung. Zwei Jahre später wechselte ich als Baureferent ins Büro Bürgermeister Mag. Siegfried Nagl.

Im Oktober 2011 erreichte ich ein für mich lang ersehntes Ziel: Nach einem Hearing wurde ich als Spartenbereichsleiter der Holding Graz Wasserwirtschaft bestellt und bin seither hauptverantwortlich für die Wasserver- und Abwasserentsorgung der Landeshauptstadt Graz. Nahezu 200 Kolleginnen und Kollegen stehen mir dabei zur Seite. Graz bezieht zu rund einem Viertel Wasser vom Südlichen Hochschwabgebiet, das von der Zentral-Wasserversorgung Hochschwab Süd GmbH. trans- portiert wird; hier bin ich auch seit Juni 2012 Geschäftsführer. Seit über fünf Jahren fungiere ich als Obmann-Stellvertreter beim Wasserverband Umland Graz und als Kassier beim Steirischen Wasserversorgungsverband. Im heurigen Sommer durfte ich die Funktion als Obmann-Stellvertreter bei der Gemeinschaft Steirischer Abwasserentsorger übernehmen.

\section{Seit wann sind Sie für den ÖWAV tätig? Was waren Ihre wesentlichsten Stationen im ÖWAV?}

Erste Kontakte mit dem ÖWAV knüpfte ich vor rund 25 Jahren im Zuge meiner Tätigkeit im Kanalbauamt der Stadt Graz. Ich durfte damals, in Vertretung des Amtsleiters, an Sitzungen des ÖWAVs teilnehmen und die Erfahrungen aus der Abwasserentsorgung der Stadt Graz aus verschiedensten Themenbereichen (Hauskanal, Indirekteinleiter, Abwasserreinigung) einbringen. Damals wurde mir als junger Techniker erstmals bewusst, wie wichtig eine Dachorganisation ist, die die Interessen der Kanalnetzbetreiber bzw. Abwasserentsorger vertritt.

So richtig eingestiegen bin ich in den ÖWAV mit Übernahme der Spartenbereichsleitung der Holding Graz Wasserwirtschaft. So bin ich seit dem Jahr 2012 sowohl in der Fachgruppe Abwassertechnik und Gewässerschutz als auch in der ARGE Abwasser tätig. Seit dem Jahr 2015 bin ich auch im ÖWAV Vorstand vertreten.

Neben meiner Tätigkeit bzw. Mitarbeit im ÖWAV ist es mir ein besonderes Anliegen, dass Betriebsangehörige der Holding Graz Wasserwirtschaft bei Ausschüssen bzw. Arbeitsgruppen im ÖWAV aktiv mitarbeiten und so ihr Fachwissen einbringen, aber auch gleichzeitig wichtige Informationen in unseren Betrieb mitbringen können.

Ich persönlich schätze die österreichweite Vernetzung über den ÖWAV mit der Fachkollegenschaft, da dies ein wesentlicher Punkt ist, um am Ball zu bleiben. Daneben sind die unverzichtbaren Informationen der Geschäftsstelle sowie die Möglichkeit der Teilnahme an Seminaren und Tagungen und natürlich die persönlichen Informationsgespräche und der Austausch von eigenen Erfahrungen, die nicht immer laut angesprochen werden können, wesentliche Eckpfeiler einer funktionierenden Dachorganisation.

Hinweis des Verlags Der Verlag bleibt in Hinblick auf geografische Zuordnungen und Gebietsbezeichnungen in veröffentlichten Karten und Institutsadressen neutral. 